\title{
Aerodynamic Performance Estimation of Camber Morphing Airfoils for Small Unmanned Aerial Vehicle
}

\author{
T Rajesh Senthil Kumar ${ }^{1}$, Sivakumar Venugopal ${ }^{1, *}$, Balajee Ramakrishnananda ${ }^{1}$, S. Vijay ${ }^{1}$ \\ How to cite
}

Kumar TRS (D) https://orcid.org/0000-0002-7151-9497

Venugopal S (D) https://orcid.org/0000-0001-9049-7599

Ramakrishnananda B (D) https://orcid.org/0000-0002-4430-9697

Kumar TRS; Venugopal S; Ramakrishnananda B; Vijay S (2020) Aerodynamic Performance Estimation of Camber Morphing Airfoils for Small Unmanned Aerial Vehicle J Aerosp Tecnol Manag, 12: e1420. doi: 10.5028/jatm.v12.1094.

\begin{abstract}
This paper proposes a methodology to harvest the benefits of camber morphing airfoils for small unmanned aerial vehicle (SUAV) applications. Camber morphing using discrete elements was used to morph the base airfoil, which was split into two, three, and four elements, respectively, to achieve new configurations, into the target one. . In total, thirty morphed airfoil configurations were generated and tested for aerodynamic efficiency at the Reynolds numbers of $2.5 \times 10^{5}$ and $4.8 \times 10^{5}$, corresponding to loiter and cruise Reynolds numbers of a typical SUAV. The target airfoil performance could be closely achieved by combinations of 5 to 8 morphed configurations, the best of which were selected from a pool of thirty morphed airfoil configurations for the typical design specifications of SUAV. Interestingly, some morphed airfoil configurations show a reduction in drag coefficient of 1.21 to $15.17 \%$ compared to the target airfoil over a range of flight altitudes for cruise and loiter phases. Inspired by the drag reductions observed, a case study is presented for resizing a SUAV accounting for the mass addition due to the morphing system retaining the benefits of drag reduction.
\end{abstract}

KEYWORDS: Camber morphing, SUAV design, Drag reduction, Aerodynamic efficiency.

\section{INTRODUCTION}

Recently, research in the area of morphing is gaining a lot of attention in the aerospace domain (Barbarino et al. 2011; Vasista et al. 2012; Friswell 2014). The word "morphing" derives its meaning from the Greek root of metamorphoses, which implies change (Barbarino et al. 2011). Wing morphing enables us to extend the flight envelope, and reduce the need to use traditional control surfaces. Conventionally, aircrafts are designed to give optimum performance for a narrow range of flight conditions. Morphing the wing shape enables an aircraft to give optimized performance over a wider margin of flight conditions. The morphing of the wing shape can be categorized into three types, namely: planform, airfoil, and out-of plane morphing (Barbarino et al. 2011; Vasista et al. 2012; Friswell 2014). Modifying parameters, such as thickness or camber, can be considered as airfoil morphing. Keeping the thickness constant and varying the camber is called camber morphing (Barbarino et al. 2011; Vasista et al. 2012; Friswell 2014).

Camber morphing helps enhancing the maximum lift coefficient, and increasing the aerodynamic efficiency, which directly affects the range and endurance. This finds extensive applications in SUAV, usually operated in Reynolds numbers of the order of $10^{5}$, and can be used for both civil and defense applications (Friswell 2014; Poonsong 2004; Wang 2015). Camber morphing using multiple elements for unmanned aerial vehicles has been previously researched by Poonsong (2004), Ko et al. (2014) and Wang (2015). The baseline airfoil was split into 6 elements and connected by revolute joints. Pneumatic actuators, servomotors and shape memory alloys work in tandem to enable this mechanism (Poonsong 2004; Ko et al. 2014; Wang 2015). An aerodynamic

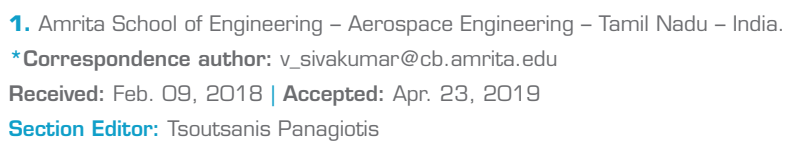


efficiency higher than that of the traditional plain flap models was observed (due to the rise in the lift coefficients instead of in the drag ones) for the camber morphed airfoil used in place of a flap (Poonsong 2004; Ko et al. 2014; Wang 2015). Poonsong (2004) also noted that the multi-element camber morphing airfoil generated, while morphing a base airfoil of NACA 0012 to target airfoil of NACA 9312, high drag due to skin friction.

Taking inspiration from a fish skeleton, Woods et al. (2014) developed FishBAC airfoil, from NACA 0012. FishBAC morphing airfoil produced 20 to $25 \%$ higher aerodynamic efficiency than traditional flapped airfoils. Ajaj et al. (2016) observed that the morphing parameters have to be accounted for during early design phase of an aircraft rather than retrofitting. Leoviriyakit and Jameson (2004) optimized the wing planforms of long range transport aircraft through adjoint-based optimization technique. For the given Mach number and wing lift coefficient at cruise mission, wing planforms of various commercial aircrafts were optimized to have low drag without weight penalty in the design. These optimized planforms showed increase in lift-to-drag ratio, which improves the range of the aircrafts in that considered mission only.

Counsil and Boulama (2013) studied the flow over NACA 0012 and SD 7003 airfoils in the low Reynolds number regime

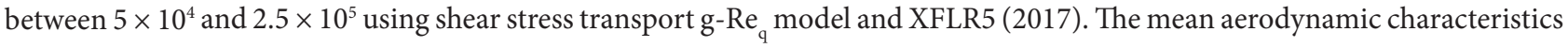
were rapidly captured with less computational time and remarkably well by XFLR5 (2017) compared to SST g-Re model. Hansen et al. (2014) noted that the presence of laminar separation bubble alters the lift curve slope at a Reynolds number of $10^{5}$. Aftab et al. (2016) studied the selection of turbulence model for low Reynolds number flows. In this work, it was found that the SST g-Re ${ }_{q}$ model is suited for the low Reynolds number applications in external flow. Morgado et al. (2016) predicted the performance of airfoils in the Reynolds number of the order of $10^{5}$ using XFOIL (2013) source code for XFLR5 (2017). Turbulence models with transition predicts characteristics in Computational Fluid Dynamics (CFD), like Shear Stress Transport $k-\omega$ (SST $k-\omega)$ model and Transitional Shear Stress Transport (TSST). It was clearly revealed that the XFOIL (2013) code predicts the aerodynamic performances better than other CFD codes in the Reynolds number of the order of $10^{5}$ when compared with available experimental results. Accumulation of the numerical errors with high meshing and uncertainties in turbulence modeling are possible sources of error in CFD. On the other hand, any experimental work in a wind tunnel entails uncertainties in hysteresis effects, tip leakages, wind tunnel boundary layer effects and measurement errors. Still, the reasons for better performance of XFOIL (2013) code cannot be completely justified. T Rajesh Senthil Kumar et al. (2017) studied the performance of two-element camber airfoil using TSST model and XFLR5 (2017), and found that XFLR5 (2017) predicts the mean aerodynamic characteristics well with less CPU time than the TSST model.

It was understood, from the previous works, that there is continuous strive to achieve optimum performance during the flight mission. It was shown that optimized wing planform is possible without mass/weight penalty in the design for a particular mission segment of the flight (Leoviriyakit 2004). The above mentioned optimum geometry and performance through adjointbased optimization can be obtained in real time through morphing. What is more, morphing the aircraft wing geometry during the flight enables the realization of optimized flight performance over a wider margin of flight conditions. It has been observed that camber morphing is one of the best and simplest ways to achieve the optimized performance over the entire mission (Barbarino et al. 2011; Vasista et al. 2012; Friswell 2014; Poonsong 2004; Ko et al. 2014; Wang 2015; Woods et al. 2014). There has been much interest shown by researchers (Ko et al. 2014; Wang 2015; Woods et al. 2014) on morphing the flaps by integrating it with the wing, aiming to have smooth continuous wing, and also morphing an airfoil into another one (Poonsong 2004).

It was noted in several of the aforementioned works that the NACA 0012 is a suitable choice for a base airfoil, because its symmetric geometry and thickness is enough to hold the morphing mechanism for chord ranges between 0.24 to $0.305 \mathrm{~m}$, which is used in SUAV (Short 2008; Woods et al. 2014; Ajaj et al. 2016). Discretizing a base airfoil into six elements increases the number of movable parts and mechanical links in the morphing mechanism, resulting that the complex morphing mechanism morphs the airfoil and increases the mass of the system, which allows for more energy for actuation. This increase in mass leads to mass penalty, which may outweigh the aerodynamic performance increment. Therefore, it is not practically feasible to use many elements for SUAV. It is necessary to find an optimum number of elements, which balance both the contradicting requirements of a high degree of flexibility in morphing and the need to reduce complex morphing mechanisms (with its associated weight). In the current work, a maximum of four elements are used for morphing. 
This paper explores ways to morph an airfoil through discrete element camber morphing methodology and evaluates their performance benefits for typical mission specifications of SUAV. The base airfoil was divided into two, three and four elements, based on the geometric details of the target airfoil. Discrete element camber morphing concept attempts to morph a base airfoil to attain aerodynamic performance equivalent to that of the target airfoil. The base airfoil selected for this study was NACA 0012 (Poonsong 2004; Woods et al. 2014). Although general data for many SUAV are available, the data of airfoils specifically used for SUAV are not. One exception is the LAURA SUAV, which uses Eppler 201 (E201) airfoil (Cross 1989). Furthermore, E201 is a low Reynolds number airfoil that has a maximum thickness equivalent to the base airfoil NACA 0012. Hence, E201 was chosen as target airfoil. In total, thirty morphed airfoil configurations were generated by adjusting the camber-line of the NACA 0012 at multiple locations along the chord. The performances of these airfoils were computed in cruise and loiter Reynolds number of a typical SUAV, using XFLR5 (2017). The advantage of using morphing airfoils for SUAV is illustrated through a case study, and modifications are suggested to the design parameters of a typical SUAV, taking into account the mass penalty imposed by the morphing system

\section{MORPHING AIRFOIL AND SIMULATION SETUP}

This section details the development of morphed airfoil configurations through discrete element camber morphing concept, and their performance estimation in low Reynolds number flows. XFLR5 Ver.6.10 (2017) and ANSYS ${ }^{\circledR}$ FLUENT 14.0 (2014) are used to simulate the flow over the airfoil. Accuracy of the solution and computation time required for said simulation are also studied and reported.

\section{MORPHING CONCEPT AND GEOMETRY}

The base airfoil was morphed into another one by a discrete element camber morphing approach, through which the amount of camber varied without modifying the thickness of an airfoil. In general, the amount of camber shifts the lift curve of an airfoil towards the left without altering its slope, and the amount of thickness alters peak pressure coefficient at the leading edge, as well as delays the occurrence of the stall. The position and amount of maximum camber and maximum thickness were definite and permanent for an airfoil. Conventional plain flaps are positioned after $75 \%$ of the chord of an airfoil, which are used to alter the camber of it. The base airfoil was morphed equivalent to that of the target one, whose performance was used as yardstick to evaluate aerodynamic performance of morphed airfoils. Locations for morphing were selected based on the target airfoil geometry and the position of conventional plain flap. The first and second locations were chosen as the maximum camber position and the maximum thickness position of the target airfoil. The third position was chosen as that of the hinge of a typical plain flap, which is around $75 \%$ of the chord. The target and base airfoils are chosen in such a way that their maximum thickness-to-chord ratio are almost the same. Eppler 201 has maximum camber of $3.1 \%$ of chord occurs at $44.5 \%$ of the chord. And it has maximum thickness of $11.98 \%$ of chord at $32 \%$ of the chord.

NACA 0012 was discretized into two-, three-, and four-element formations. The morphing location of the two-element formation was fixed at 45\% (position "A") of the chord, as shown in Figs.1 and 2a. Two elements rotate with respect to position "A" where $\theta_{\mathrm{A} 1}$ and $\theta_{\mathrm{A} 2}$ indicate the angular positions of first and second element. The two morphing locations for the threeelement formation were chosen to be at 32\% (position "B") and $45 \%$ (position "A") of the chord. The first element rotates $\theta_{\mathrm{B} 1}$ about position " $\mathrm{B}$ " and the third element rotates $\theta_{\mathrm{A} 2}$ about the position "A", as seen in Figs. 1 and $2 \mathrm{~b}$. The three morphing locations for the four-element formation were at 32\% (position "B"), 45\% (position " $\mathrm{A}$ ") and 75\% (position " $\mathrm{C}$ ”) of the chord, as depicted in Fig. 1. Similarly, $\theta_{\mathrm{B} 1}$ and $\theta_{\mathrm{A} 2}$ represent the angular positions of first and third element about position "B" and position "A" respectively, and the fourth element rotates $q_{\mathrm{C} 3}$ about the position " $\mathrm{C}$ ", as displayed in Figs. 1 and $2 \mathrm{c}$. The $3 \mathrm{D}$ models in the Figs. 2a to c, and 2D representation of morphed airfoils in Fig. 2d are used here for illustration purposes only, while the simulations are done for $2 \mathrm{D}$ only. 


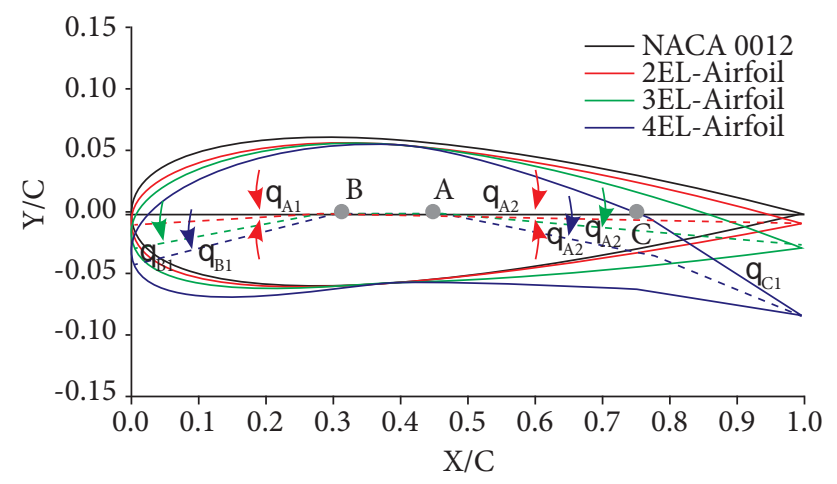

Figure 1. Representation of discrete element morphing.

The maximum camber of the target airfoil (3.1\% of chord) confines the maximum angle by which each element of the base airfoil should turn to attain the equivalent shape and performance of the target airfoil. The maximum morphing angles limit is set as $6^{\circ}$ for the elements, based on the maximum camber of the target airfoil. Morphing angles at positions such as A, B, and C varies from 1 to $6^{\circ}$ to generated low-high cambered morphed airfoils. The remaining morphing angles tweaked to generate morphed airfoil of geometry and performance equivalent to that of the target one. For each formation, ten morphed airfoil configurations are generated. In total, thirty configurations for three formations were generated, as listed in Table 1. The morphed airfoils are named in such way that the first three letters represent the formations, and the fourth place represents the variations in each formation, as displayed in Table 1. For example, in "2ELI", the first three letters, "2EL", indicate two-element formation, and the Roman numeral "I" in the fourth place indicates the variation.

(a)

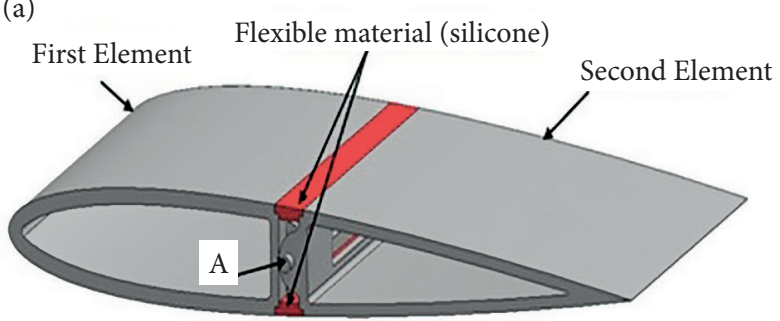

(c)

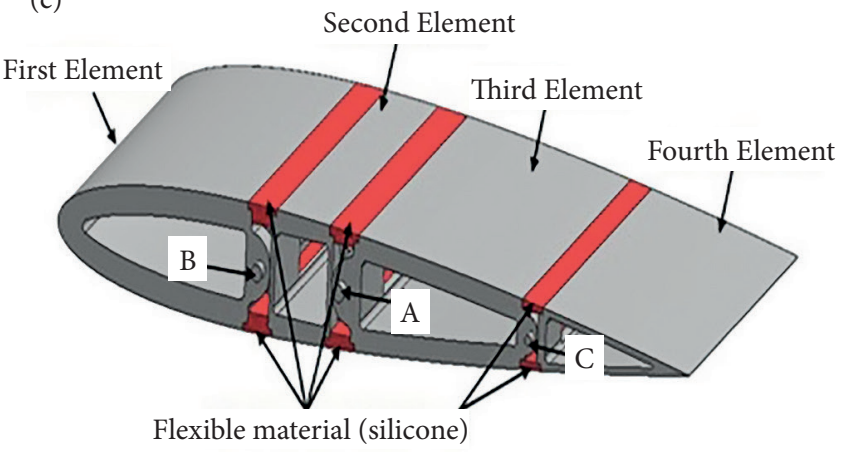

Four Element Formation (b)

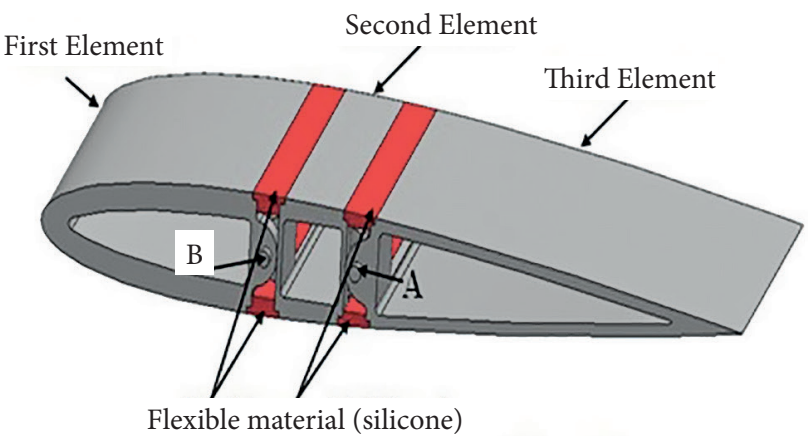

(d)
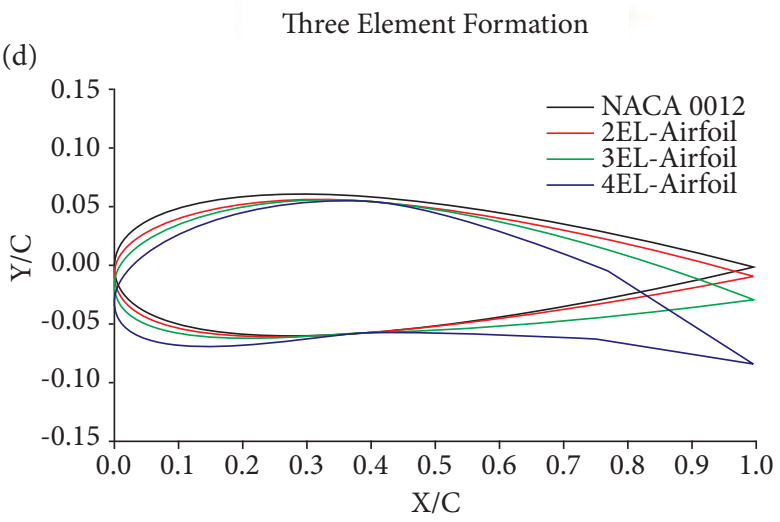

Morphed airfoils and Target airfoil

Figure 2. Representation of camber morphing airfoil (geometry). 
Table 1. Geometric details of morphed airfoil configurations.

\begin{tabular}{|c|c|c|c|c|c|c|c|c|c|}
\hline \multirow{3}{*}{$\begin{array}{l}\text { Airfoil } \\
\text { name }\end{array}$} & \multirow{2}{*}{\multicolumn{2}{|c|}{$\begin{array}{c}\text { Two-element } \\
45 \% \text { C }\end{array}$}} & \multirow{3}{*}{$\begin{array}{l}\text { Airfoil } \\
\text { name }\end{array}$} & \multicolumn{2}{|c|}{ Three-element } & \multirow{3}{*}{$\begin{array}{l}\text { Airfoil } \\
\text { name }\end{array}$} & \multicolumn{3}{|c|}{ Four-element } \\
\hline & & & & \multirow{2}{*}{$\begin{array}{l}32 \% \mathrm{C} \\
\theta_{\mathrm{B} 1} \text { deg }\end{array}$} & \multirow{2}{*}{$\begin{array}{l}45 \% \mathrm{C} \\
\theta_{\mathrm{A} 2} \text { deg }\end{array}$} & & \multirow{2}{*}{$\frac{32 \% \mathrm{C}}{\theta_{\mathrm{B} 1} \mathrm{deg}}$} & \multirow{2}{*}{$\begin{array}{l}45 \% \mathrm{C} \\
\theta_{\mathrm{A} 2} \mathrm{deg}\end{array}$} & \multirow{2}{*}{$\frac{75 \% \mathrm{C}}{\theta_{\mathrm{c} 3} \mathrm{deg}}$} \\
\hline & $\theta_{A 1} \operatorname{deg}$ & $q_{A 2}$ deg & & & & & & & \\
\hline $2 \mathrm{ELI}$ & 1 & 1 & 3ELI & 1 & 1 & $4 \mathrm{ELI}$ & 1 & 1 & 1 \\
\hline 2ELII & 2 & 2 & 3ELII & 2 & 2 & $4 \mathrm{ELII}$ & 2 & 2 & 2 \\
\hline 2ELIII & 3 & 3 & 3ELIII & 3 & 3 & 4ELIII & 3 & 3 & 3 \\
\hline 2ELIV & 4 & 4 & 3ELIV & 4 & 4 & 4ELIV & 4 & 4 & 4 \\
\hline $2 \mathrm{ELV}$ & 5 & 5 & $3 \mathrm{ELV}$ & 5 & 5 & $4 \mathrm{ELV}$ & 5 & 5 & 5 \\
\hline 2ELVI & 6 & 6 & 3ELVI & 6 & 6 & 4ELVI & 6 & 6 & 6 \\
\hline 2ELVII & 2 & 3 & 3ELVII & 4 & 3 & 4ELVII & 2 & 3 & 3 \\
\hline 2ELVIII & 3.5 & 3 & 3ELVIII & 5 & 3 & 4ELVIII & 4 & 3 & 3 \\
\hline 2ELIX & 3.5 & 3.2 & 3ELIX & 5.5 & 3 & 4ELIX & 5 & 3.5 & 3 \\
\hline $2 \mathrm{ELX}$ & 3.9 & 3.2 & $3 \mathrm{ELX}$ & 5.5 & 3.2 & $4 \mathrm{ELX}$ & 5.5 & 3.8 & 3.2 \\
\hline
\end{tabular}

Simulation Setup; C= Chord

XFLR5 (2017) is the graphical user interface for the XFOIL (2013) code, developed by Drela (1989), and requires the airfoil co-ordinates for the simulation. The panels were modelled over the airfoil based on the given co-ordinates. XFLR5 (2017) uses cosine distribution function to cluster more number of panels near the leading and trailing edges of the airfoil. A maximum of 200 panels is used for the simulations in XFLR5 (2017), which solves the potential panel method coupled with interactive boundary layer equations, along with the transition model $e^{\mathrm{N}}$ over each panel of the airfoil (Derla 1989; Van Ingen 2008). CFD simulation using ANSYS ${ }^{\circledR}$ FLUENT (2014) requires C-H domain, whose boundaries were 20 times the airfoil chord, as shown in Fig. 3. Quadrilateral elements are used to mesh the computational domain, and the elements growth is controlled to have the wall $y^{+}$less than one over the airfoil. ANSYS ${ }^{\circledR}$ FLUENT (2014) solves the discretized TSST equation in each cell of the computational domain (Langtry and Menter 2005; Menter et al. 2006; Langtry et al. 2006). Table 2 shows the inputs for ANSYS ${ }^{\circledR}$ FLUENT and XFLR5.

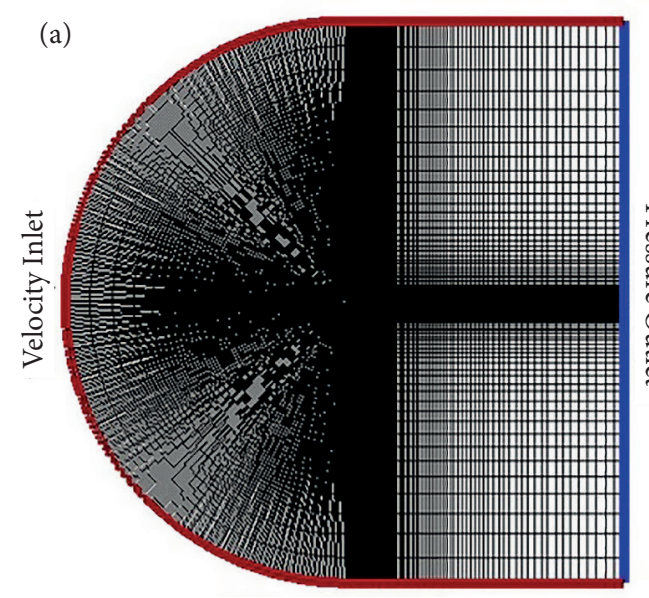

Domain with Mesh

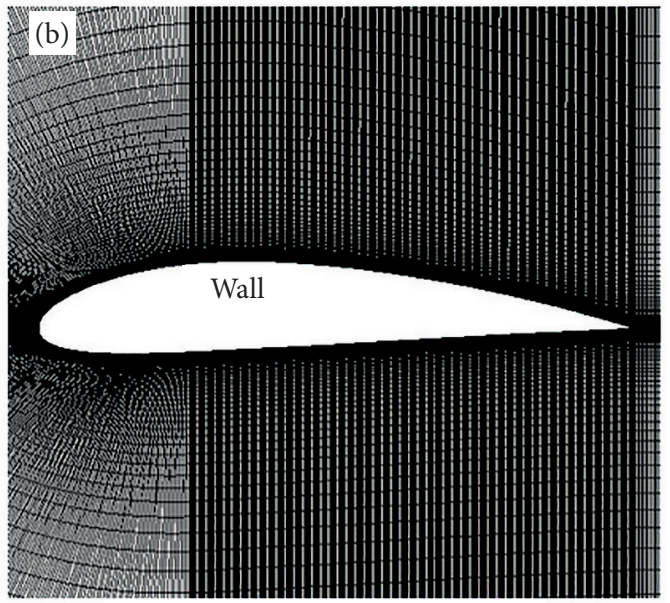

Zoomed Mesh NACA 4415

Figure 3. Domain used for simulation and mesh generation. 
Table 2. Settings for ANSYS FLUENT 14.0 and XFLR5.

\begin{tabular}{|c|c|c|c|}
\hline Type & ANSYS & Type & XFLR5 \\
\hline Viscous model & Transition SST & N factor (based on turbulent intensity) & Newton iterative \\
\hline Turbulent intensity & $0.11 \%$ & Algorithm & Cosine \\
\hline Algorithm & SIMPLE & Discretization & \\
\hline Discretization scheme & Second order & & \\
\hline Fixed time step & $1 \times 10^{-4}$ & & \\
\hline
\end{tabular}

\section{VALIDATION STUDY}

NACA 0021 and NACA 4415 airfoils are used for validating the results from XFLR5 (2017) and ANSYS ${ }^{\circledR}$ FLUENT (2014). Experimental data are available in literature for these airfoils at 5 and $6^{\circ}$ angles of attack (AoA) at a Reynolds number of $1.2 \times 10^{5}$ (Aftab et al. 2016; Hansen et al. 2014). Every simulation in ANSYS ${ }^{\circledR}$ FLUENT (2014) ran for 18 hours in a machine with processor Intel ${ }^{\circledR}$ Core i7-7700k with $4.20 \mathrm{GHz}$ and $16 \mathrm{~Gb}$ RAM, in order to obtain the solution. Data for 4000 time steps are stored and averaged over a time interval of $0.4 \mathrm{~s}$, aiming to obtain the time average pressure coefficients. XFLR5 (2017) generates the results faster and with much lower computation time when compared to ANSYS ${ }^{\circledR}$ FLUENT (2014). Figures 4 and 5 present the grid converged pressure coefficient distribution from XFLR5 (2017) and ANSYS ${ }^{\circledR}$ FLUENT (2014) for NACA 4415 and NACA 0021. It was noted that, from 150 panels onwards, the solutions from the XFLR5 (2017) remain the same until 200 panels for both airfoils, as shown in Fig. 4. Hence, the number of panels was fixed in 200. What is more, the solution from ANSYS ${ }^{\circledR}$ FLUENT (2014) shows convergence from 0.13 million cells onwards, as displayed in Fig. 5. Therefore, computational domain with 0.17 million cell was commonly selected for both airfoils in Figs. 4 and 5. Figure 6 shows the comparison of pressure coefficient distribution from XFLR5 (2017) and ANSYS ${ }^{\circledR}$ FLUENT (2014) with experimental data from literature. It is noted that solutions obtained from the current simulation match closely the experimental data. XFLR5 (2017) predicts the transition location of the flow closer to that of experimental values compared to the ANSYS ${ }^{\circledR}(2014)$ solution. Table 3 shows the difference in percentage error between experimental results and simulation results for two position, $S_{\mathrm{p}}$ and $T_{\mathrm{p}}$, along the chord of an airfoil. It can be seen that XFLR5 (2017) is better in predicting the mean aerodynamic coefficients with less computational effort compared to ANSYS ${ }^{\circledR}$ FLUENT (2014), as listed in Table 3. One of the possible reasons for XFLR5 (2017) to predict the results better is that the panels are the line connecting two points placed over the airfoil, which creates a mesh simpler than the CFD solvers, probably resulting in less numerical errors than them.
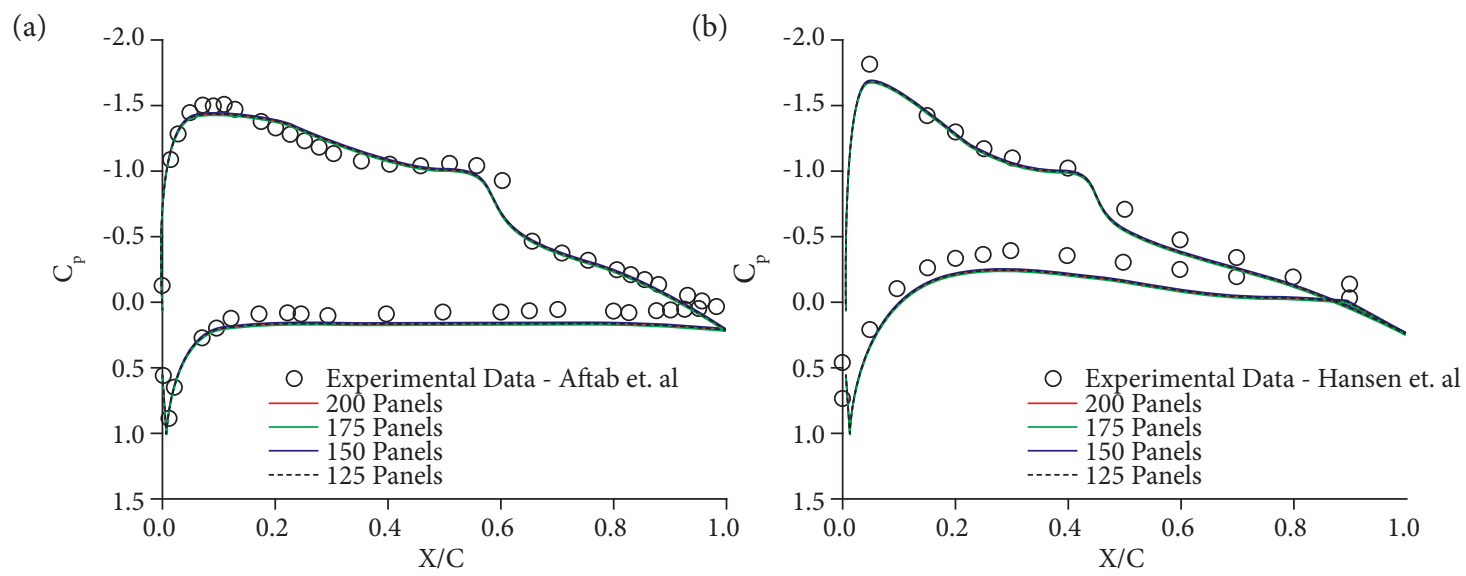

Figure 4. Grid convergence for XFLR5 results: pressure coefficients. (a) NACA 4415 at 6॰ AoA; (b) NACA 0021 at $5^{\circ}$ AoA. 
(a)

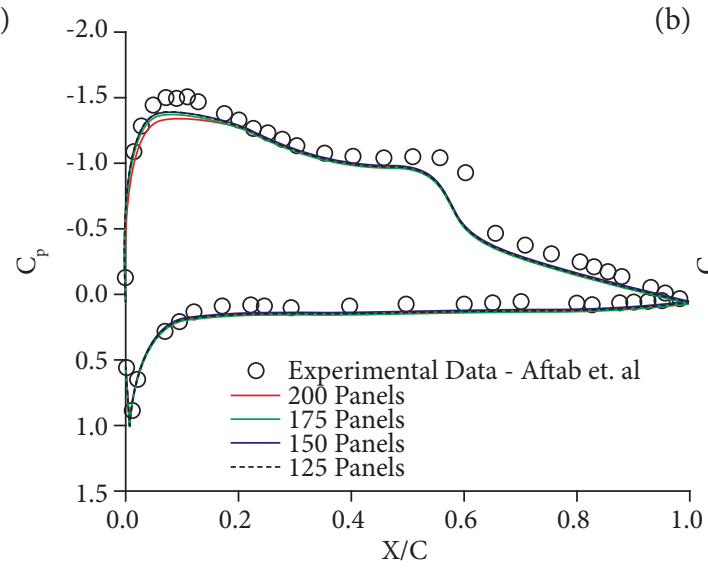

(b)

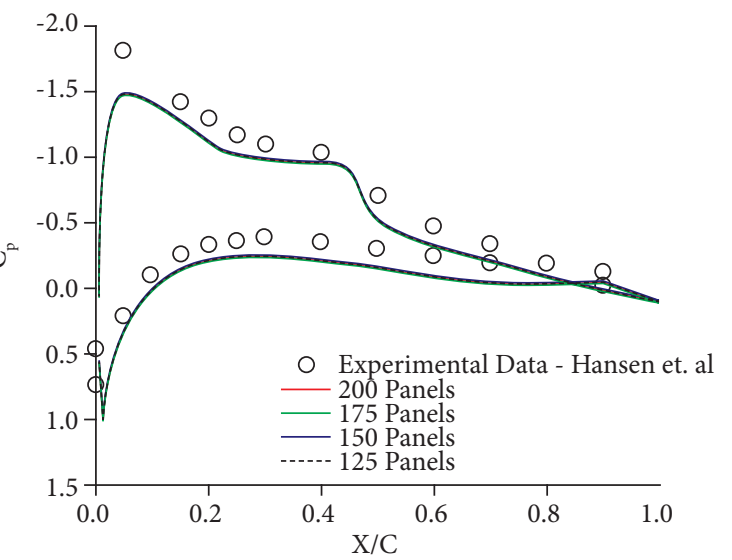

Figure 5. Grid convergence for CFD results: pressure coefficients. (a) NACA 4415 at 6॰ AoA; (b) NACA 0021 at $5^{\circ}$ AoA.

(a)

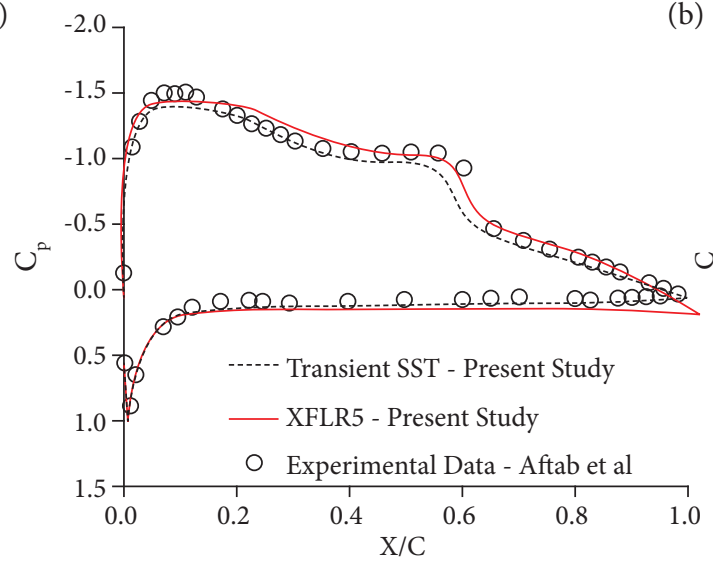

(b)

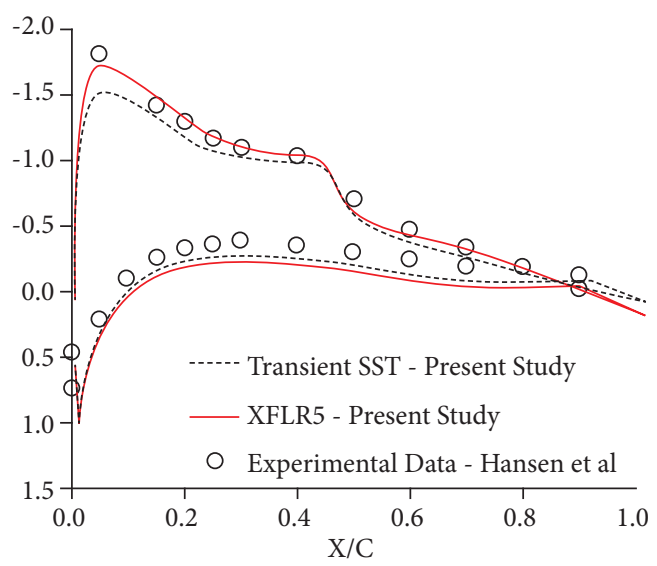

Figure 6. Comparison of pressure coefficients. (a) NACA 4415 at $6^{\circ} \mathrm{AoA}$; (b) NACA 0021 at $5^{\circ}$ AoA.

Table 3. Percentage error difference between experiment and simulation results.

\begin{tabular}{|c|c|c|c|c|}
\hline \multirow{2}{*}{ Location along the chord } & \multicolumn{2}{|c|}{ NACA 4415 } & \multicolumn{3}{|c|}{ NACA 0021 } \\
\cline { 2 - 5 } & XFLR5 & CFD & XFLR5 & CFD \\
\hline Suction peak $\left(S_{\mathrm{p}}\right)$ & $3.67 \%$ & $6.92 \%$ & $6.58 \%$ & $16.60 \%$ \\
\hline Transition point $\left(T_{\mathrm{p}}\right)$ & $4.99 \%$ & $5.80 \%$ & $1.95 \%$ & $4.78 \%$ \\
\hline
\end{tabular}

\section{RESULTS AND DISCUSSIONS}

\section{COMPARISONS OF MORPHED CONFIGURATIONS WITH TARGET AIRFOIL}

The base airfoil is configured into two-, three-, and four-element formations to achieve shape morphing of the airfoil. Ten morphed airfoil shapes are generated from each formation. Overall, thirty shapes are generated and tested along with base and target airfoils at the Reynolds numbers corresponding to loiter and cruise phases of a typical SUAV using XFLR5 (2017). The loiter and cruise Reynolds numbers chosen are $2.5 \times 10^{5}$ and $4.8 \times 10^{5}$, respectively. The aerodynamic performances of all 32 airfoils were evaluated over the AoA range from $-4^{\circ}$ to $16^{\circ}$, with an increment of $0.5^{\circ}$. An airfoil database was created using MYSQL (2018) - an open source database software to store the performance of these 32 airfoils. In-house MATLAB ${ }^{\circledR}$ (2018) code was written to interact with MYSQL (2018) server, in order to retrieve data whenever necessary. 
The aerodynamic performance of the morphed airfoil shapes were compared with the target airfoil (Eppler 201). It is interesting to note that the performance of the target airfoil is almost achieved by a group of morphed airfoils from the two-, three- and four-element formations. A single morphed airfoil may achieve the performance of the target one over a limited range of AoA, but cannot achieve the same over a wider AoA range. A set of morphed airfoils from each formation are identified to achieve the target airfoil aerodynamic efficiency (i. e., lift-to-drag ratio), and listed in Tables 4 and 5. It is to be noted that aerodynamic efficiency is one of the crucial performance parameters, which directly affects the range and endurance of the SUAV.

Table 4. Set of morphed airfoils based on $c_{1} / c_{d}$ ratio for $R e=2.5 \times 10^{5}$.

\begin{tabular}{|c|c|c|c|c|c|}
\hline \multicolumn{2}{|c|}{ Two-element airfoils } & \multicolumn{2}{|c|}{ Three-element airfoils } & \multicolumn{2}{|c|}{ Four-element airfoils } \\
\hline AoA deg & Airfoil & AoA deg & Airfoil & AoA deg & Airfoil \\
\hline-4 to -0.5 & 2ELIV & -4 to -1.5 & 3ELIV & -4 to 3.5 & 4ELII \\
\hline 0 to 4 & 2ELVII & -1 to -0.5 & $3 \mathrm{ELV}$ & 4 & 4ELVII \\
\hline 4.5 & 2ELIII & 0 to 1 & 3ELIV & 4.5 & 4ELIII \\
\hline 5 & 2ELIV & 1.5 to 4.5 & 3ELIII & 5 & 4ELVIII \\
\hline 5.5 & $2 \mathrm{ELV}$ & 5 & 3ELIV & 5.5 to 8.5 & $4 \mathrm{ELX}$ \\
\hline 6 to 7 & 2ELVI & 5.5 & $3 \mathrm{ELV}$ & 9 to 11 & $4 \mathrm{ELI}$ \\
\hline 7.5 to 10.5 & $2 \mathrm{ELX}$ & 6 & 3ELVI & 11.5 & 4ELIX \\
\hline 11 & 2ELIV & 6.5 to 10.5 & 3ELX & 12 & $4 \mathrm{ELX}$ \\
\hline 11.5 & $2 \mathrm{ELV}$ & 11 & 3ELIII & 12.5 to 16 & 4ELIV \\
\hline 12 to 13.5 & 2ELVI & 11.5 & 3ELIV & & \\
\hline \multirow[t]{2}{*}{14 to 16} & 2ELVII & 12 to 12.5 & $3 \mathrm{ELV}$ & & \\
\hline & & 13 to 16 & 3ELVI & & \\
\hline
\end{tabular}

Table 5. Set of morphed airfoils based on $C_{1} / C_{d}$ ratio for $\mathrm{Re}=4.8 \times 10^{5}$.

\begin{tabular}{|c|c|c|c|c|c|}
\hline \multicolumn{2}{|c|}{$\begin{array}{l}\text { Two-element } \\
\text { airfoils }\end{array}$} & \multicolumn{2}{|c|}{$\begin{array}{l}\text { Three-element } \\
\text { airfoils }\end{array}$} & \multicolumn{2}{|c|}{$\begin{array}{l}\text { Four-element } \\
\text { airfoils }\end{array}$} \\
\hline AoA deg & Airfoil & AoA deg & Airfoil & AoA deg & Airfoil \\
\hline-4 to 0 & 2ELIV & -4 to -1.5 & 3ELIV & -4 to 0 & 4ELII \\
\hline 0.5 to 3.5 & 2ELVII & -1 to 0 & 3ELV & 0.5 to 2 & 4ELVII \\
\hline 4 & 2ELIII & 0.5 to 1 & 3ELVI & 2.5 to 7.5 & 4ELX \\
\hline 4.5 & 2ELIV & 1.5 & 3ELIV & 8 to 10.5 & 4ELVII \\
\hline 5 & $2 \mathrm{ELX}$ & 2 to 2.5 & $3 \mathrm{ELV}$ & 11 to 16 & 4ELX \\
\hline 5.5 & 2ELVI & 3 to 4 & 3ELIV & & \\
\hline 6 to 9.5 & $2 \mathrm{ELX}$ & 4.5 & $3 \mathrm{ELV}$ & & \\
\hline 10 & 2ELVII & 5 to 5.5 & 3ELVI & & \\
\hline 10.5 & 2ELIV & 6 to 8 & 3ELX & & \\
\hline 11 to 12 & $2 \mathrm{ELV}$ & 8.5 to 9.5 & 3ELIX & & \\
\hline \multirow[t]{2}{*}{12.5 to 16} & 2ELVI & 10 to 11 & 3ELIII & & \\
\hline & & 11.5 to 16 & $3 \mathrm{ELV}$ & & \\
\hline
\end{tabular}


Figure 7 depicts the aerodynamic efficiency of a morphed airfoil group from each formation with the target airfoil. For the groups of three- and four-element formations, the performance closely match that of the target airfoil in the AoA range between $-4^{\circ}$ to $5.5^{\circ}$ for both Reynolds numbers of interest. The maximum aerodynamic efficiency of Eppler 201 was at the angles of attack of $6.5^{\circ}$ and $5.5^{\circ}$, respectively, for the Reynolds numbers of $2.5 \times 10^{5}$ and $4.8 \times 10^{5}$. Morphed airfoils of three- and four-element formation achieve their maximum aerodynamic efficiency at $5.5^{\circ} \mathrm{AoA}$ in the Reynolds number of $2.5 \times 10^{5}$ as shown in Fig. $7 \mathrm{a}$. The maximum aerodynamic efficiency of morphed airfoils from three- and four-element groups is only 3.5 and 4\%, respectively, lower than the Eppler 201 airfoil for the Reynolds number of $2.5 \times 10^{5}$. For number $4.8 \times 10^{5}$, maximum aerodynamic efficiency of morphed airfoils from three- and four-element groups shifts to $5^{\circ}$ and $4^{\circ}$, as shown in Fig $7 \mathrm{~b}$, which is also only 5 and $6 \%$ lower than the Eppler 201, respectively. Above $9^{\circ}$ AoA, the base airfoil showed better performance than target and morphed airfoils at the tested Reynolds numbers.
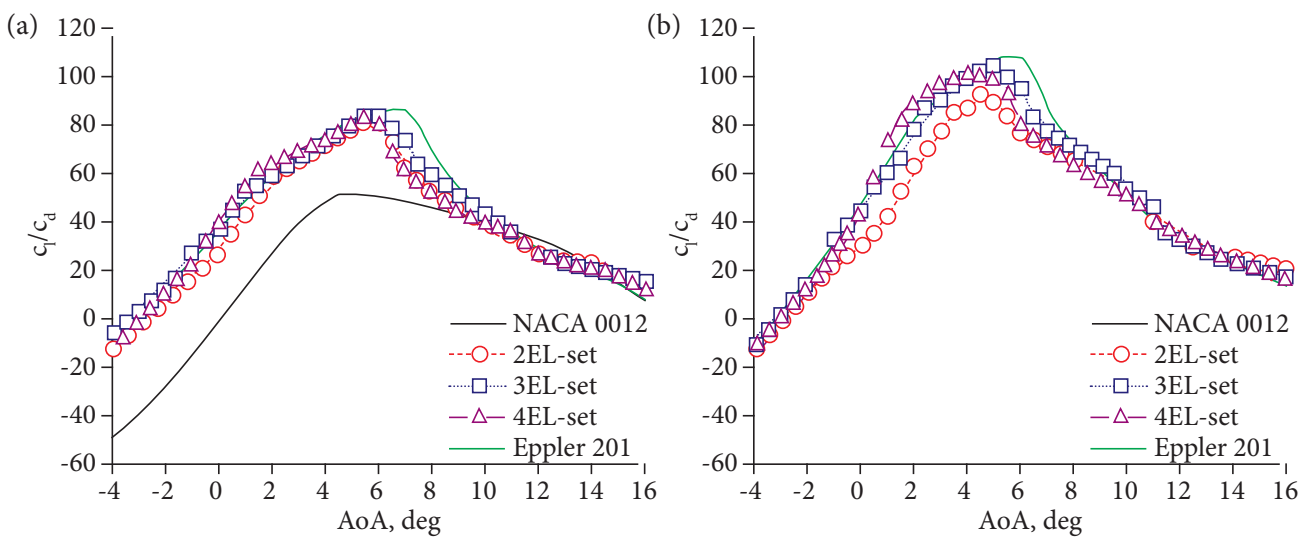

Figure 7. Aerodynamic efficiency of morphed airfoil groups with target airfoil. (a) $\operatorname{Re}=2.5 \times 10^{5}$; (b) $\operatorname{Re}=4.8 \times 10^{5}$.

Figures $7 \mathrm{a}$ and $7 \mathrm{~b}$ show that the target airfoil aerodynamic efficiency is not achieved by the morphed airfoils between $6^{\circ}$ and $8^{\circ}$ AoA. The reason can be inferred from the drag polar of these airfoils, plotted in Figs. 8a and 8b. For the same drag coefficient equivalent to target airfoil, lift coefficient was lower for the morphed airfoils, which can be seen clearly by examining the lift coefficients between 0.8 and 1.2 in Figs. 8a and 8b. Upon camber morphing the base airfoil, drag polar shifts forward as depicted in Fig. 8. From the above, it is found that camber morphing shifts the location of maximum aerodynamic efficiency to an AoA slightly lower than the target airfoil. Single performance envelope for aerodynamic efficiency and drag polar can be formed by combining the three morphed airfoil groups as listed in Tables 4 and 5, and displayed in Figs. 7 and 8. There is the possibility of attaining the same maximum aerodynamic efficiency as that of the target airfoil by selecting other morphed airfoils from the three-formations, as stressed in Table 1 . However, this leads to a drag penalty for attaining the lift augmentation, which may be acceptable, in the case, for takeoff or landing phase, probably at a different Reynolds number, not for cruise or loiter.

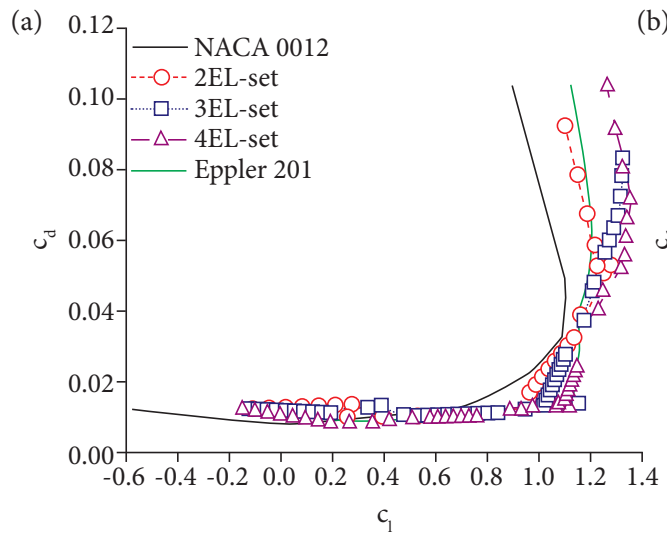

(b) 0.12

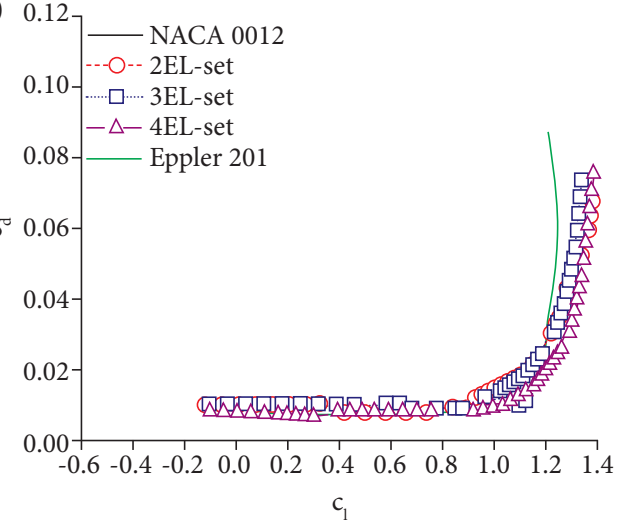

Figure 8. Drag polar of morphed airfoil groups with target airfoil. (a) $R e=2.5 \times 10^{5}$; (b) $\operatorname{Re}=4.8 \times 10^{5}$. 


\section{A CASE STUDY: SELECTION OF MORPHED AIRFOILS FOR A TYPICAL SUAV APPLICATION}

This section deald with the selection of suitable morphed airfoil for the SUAV. In general, SUAV are battery powered flyers whose maximum dimension is characterized by the wing span, which can go up to $2 \mathrm{~m}$. In steady flight, thrust should be equal to the drag of the flyer. In this case, power required from the battery is directly proportional to the product of free stream velocity $(\mathrm{U})$ and drag (D). The design parameters for generic SUAV used here are a wing loading (W/S) of $95 \mathrm{~N} / \mathrm{m}^{2}$, aspect ratio (AR) of 6 , and chord (C) of $0.2418 \mathrm{~m}$, taken from literature (Short 2008; Ajaj et al. 2016). Figure 9 shows the conceptual design of the generic SUAV. For the same loiter and cruise Reynolds numbers, morphed airfoils are selected based on the wing loading of SUAV and the altitude of the flight. The density and dynamic viscosity of air varies with the altitude (Torenbeek 2013). In-house MATLAB ${ }^{\circledR}$ (2018) code was developed to interact with MYSQL (2018) database to extract the data of morphed airfoils and to search the pool of data, in order to find the best morphed airfoil. The search was done based on the lift coefficient of airfoil. For steady flight,

$$
\begin{gathered}
\mathrm{L} / \mathrm{S}=\mathrm{W} / \mathrm{S}=0.5 \times \rho \times \mathrm{U}^{2} \times \mathrm{C}_{\mathrm{L}} \\
C_{L_{\alpha}}=a_{0} /\left[1+\frac{a_{0}}{\pi \times A R \times e}\right] \\
\mathrm{e}=1 / 1+\delta \\
\mathrm{c}_{1}=1.25 \times \mathrm{C}_{\mathrm{L}} \\
\mathrm{D}_{M B}=\left(\left(c_{d_{\text {Base }}}-c_{d_{\text {Morph }}}\right) / c_{d_{\text {Base }}}\right) \times 100 \% \\
\mathrm{D}_{M T}=\left(\left(c_{d_{\text {Targ }}}-c_{d_{\text {Morph }}}\right) / c_{d_{\text {Targ }}}\right) \times 100 \%
\end{gathered}
$$

where $\rho$ is density of air; $L$ and $S$ are lift force and planform area of the wing; $W$ is the weight of the SUAV; $C_{L \alpha}$ is the lift curve slope of finite wing; $e$ is Oswald's span efficiency factor; $\delta$ is the induced drag factor; $a_{0}=2 \pi$ is the theoretical lift curve slope of an airfoil; $C_{L}$ and $c_{l}$ are lift coefficient of the wing and the airfoil respectively; $D_{\mathrm{MB}}$ and $D_{\mathrm{MT}}$ are the percentage difference in the drag coefficient of morphed airfoils with respect to base and target airfoil; and cdBase, $c d$ Morph and cdTargare drag coefficients of base, morph and target airfoils, respectively.
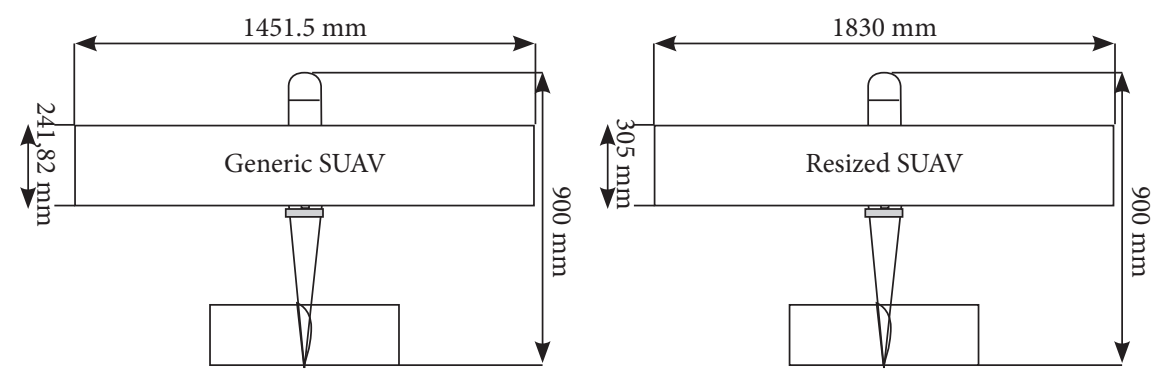

Figure 9. Conceptual representation of SUAV. 
Firstly, lift coefficient $\left(C_{L}\right)$ required for level flight of SUAV at various altitudes were computed from Eq. 1. The induced drag factor $\delta$ was taken from graph between induced drag factor variations with taper ratio of the wing of various aspect ratios (McCormick 1995). For the given aspect ratio of 6 and taper ratio of 1 for the straight wing, Oswald's span efficiency factor and the lift curve slope of straight wing were calculated using Eqs. 2 and 3. The resulting lift is $1.5 \pi$ and it differs $25 \%$ from the theoretical lift curve slope for thin airfoil (McCormick 1995). Hence, the lift coefficient of the wing was corrected by adding $25 \%$ of its value to obtain the lift coefficient of airfoil, using Eq. 4. This correction factor for estimating the lift curve slope of an airfoil using that of a wing is valid for wings with aspect ratio greater than 5 (McCormick 1995; Sadraey 2012). Table 6 lists the lift coefficients $(c l)$ required to select the morphed airfoil based on altitude. The in-house MATLAB ${ }^{\circledR}$ (2018) code searches the data pool for the required lift coefficient, and, if the exact value is not found in the database, it interpolates the data and finds the airfoil name, the angle of attack at which the lift coefficient occurs, along with the associated drag coefficient, and aerodynamic efficiency. Then, it sorts the airfoils according to drag coefficient, and writes the best morphed airfoil data with the least drag coefficient as output. The search is done to find the best morphed airfoils from each of two-, three-, and four- element formations. The least drag coefficient of the selected morphed airfoil is listed in Table 6.

Table 6. Lift coefficients for selecting morphed airfoil and drag coefficients of selected morphed airfoil.

\begin{tabular}{|c|c|c|c|c|c|c|c|c|c|}
\hline \multirow[b]{2}{*}{ Altitude[m] } & \multirow{2}{*}{$\begin{array}{l}\text { Density } \\
{\left[\mathrm{kg} / \mathrm{m}^{3}\right]}\end{array}$} & \multicolumn{4}{|c|}{$\mathrm{Re}=2.5 \times 10^{5}$} & \multicolumn{4}{|c|}{$\mathrm{Re}=4.8 \times 10^{5}$} \\
\hline & & $\begin{array}{c}\text { Velocity } \\
\text { [m/s] }\end{array}$ & $\begin{array}{c}C_{L} \\
\text { wing }\end{array}$ & $\begin{array}{c}c_{l} \\
\text { airfoil }\end{array}$ & $\begin{array}{c}c_{d} \\
\text { airfoil }\end{array}$ & $\begin{array}{c}\text { Velocity } \\
\text { [m/s] }\end{array}$ & $\begin{array}{c}C_{L} \\
\text { wing }\end{array}$ & $\begin{array}{c}c_{l} \\
\text { airfoil }\end{array}$ & $\begin{array}{c}c_{d} \\
\text { airfoil }\end{array}$ \\
\hline 0 & 1.225 & 15.102 & 0.680 & 0.8501 & 0.01101 & 28.995 & 0.184 & 0.2306 & 0.00670 \\
\hline 500 & 1.1672 & 15.710 & 0.660 & 0.8244 & 0.01082 & 30.163 & 0.179 & 0.2236 & 0.00667 \\
\hline 1000 & 1.1115 & 16.350 & 0.639 & 0.7993 & 0.01064 & 31.392 & 0.173 & 0.2168 & 0.00665 \\
\hline 1500 & 1.0579 & 17.023 & 0.620 & 0.7747 & 0.01047 & 32.685 & 0.168 & 0.2101 & 0.00662 \\
\hline 2000 & 1.0063 & 17.732 & 0.600 & 0.7506 & 0.01032 & 34.046 & 0.163 & 0.2036 & 0.00660 \\
\hline 2200 & 0.9862 & 18.027 & 0.593 & 0.7411 & 0.01027 & 34.611 & 0.161 & 0.2010 & 0.00659 \\
\hline
\end{tabular}

Figures 10 to 12 depict the drag coefficients of morphed airfoils corresponding to the required lift coefficients from two-, three-, and four-element formations. At a Reynolds number of $2.5 \times 10^{5}$ among two-element formations, 2ELIII airfoil is found to have the least drag coefficients from sea level to $1000 \mathrm{~m}$ of altitude, while 2ELVII performs better at other altitudes. 3ELIII and 4ELVII airfoils have the least drag coefficient for all the flight altitudes from three- and four-element formations. Similarly, the morphed airfoils 2ELI, 3ELI, and 4ELI, from each of the formations listed in Table 1, are found to have the least drag coefficients for the same lift coefficients, among their formations, for all the altitudes of flight considered at a Reynolds number of $4.8 \times 10^{5}$.
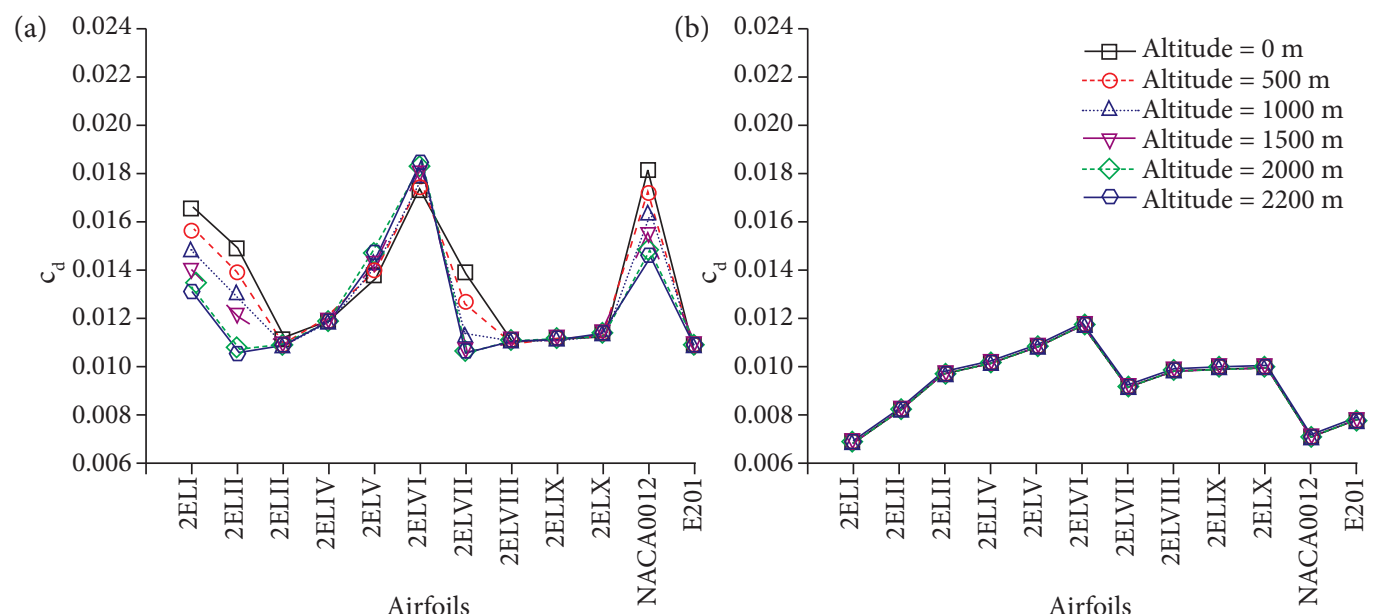

Figure 10. Drag coefficients for required lift coefficients (two-element). (a) $R e=2.5 \times 10^{5}$; (b) $\operatorname{Re}=4.8 \times 10^{5}$. 

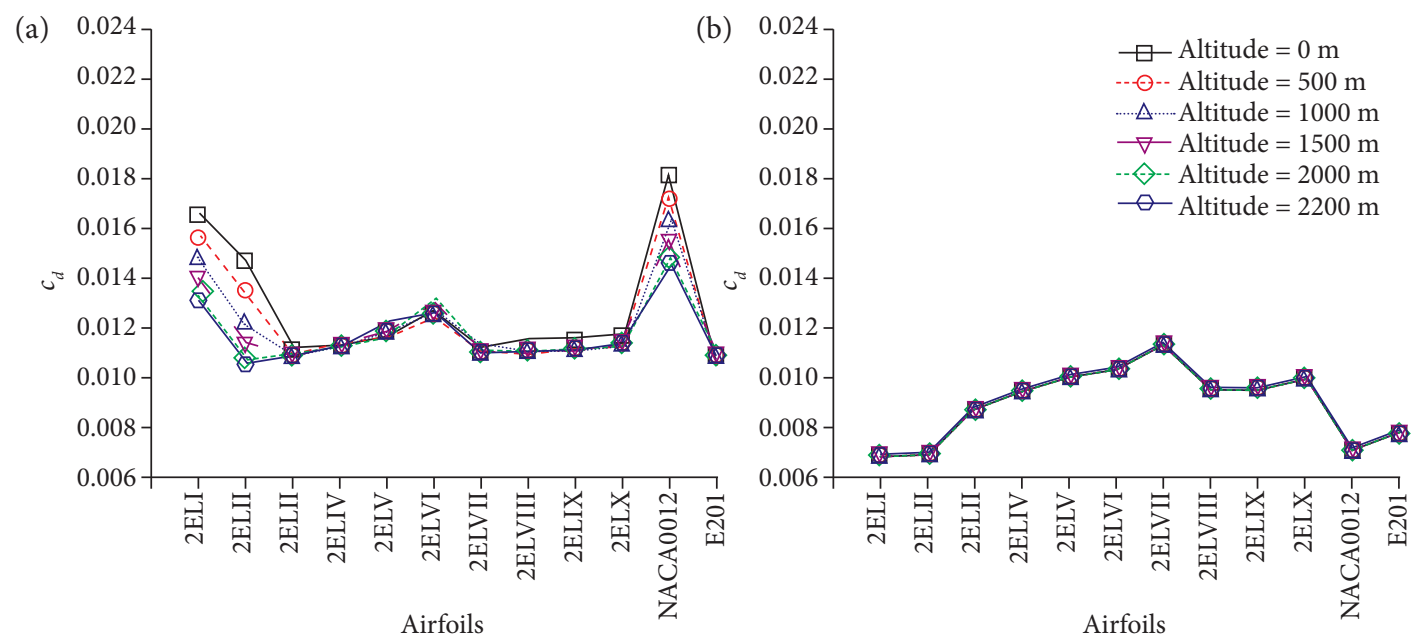

Figure 11. Drag coefficients for required lift coefficients (three-element). (a) $\operatorname{Re}=2.5 \times 10^{5}$; (b) $\operatorname{Re}=4.8 \times 10^{5}$.
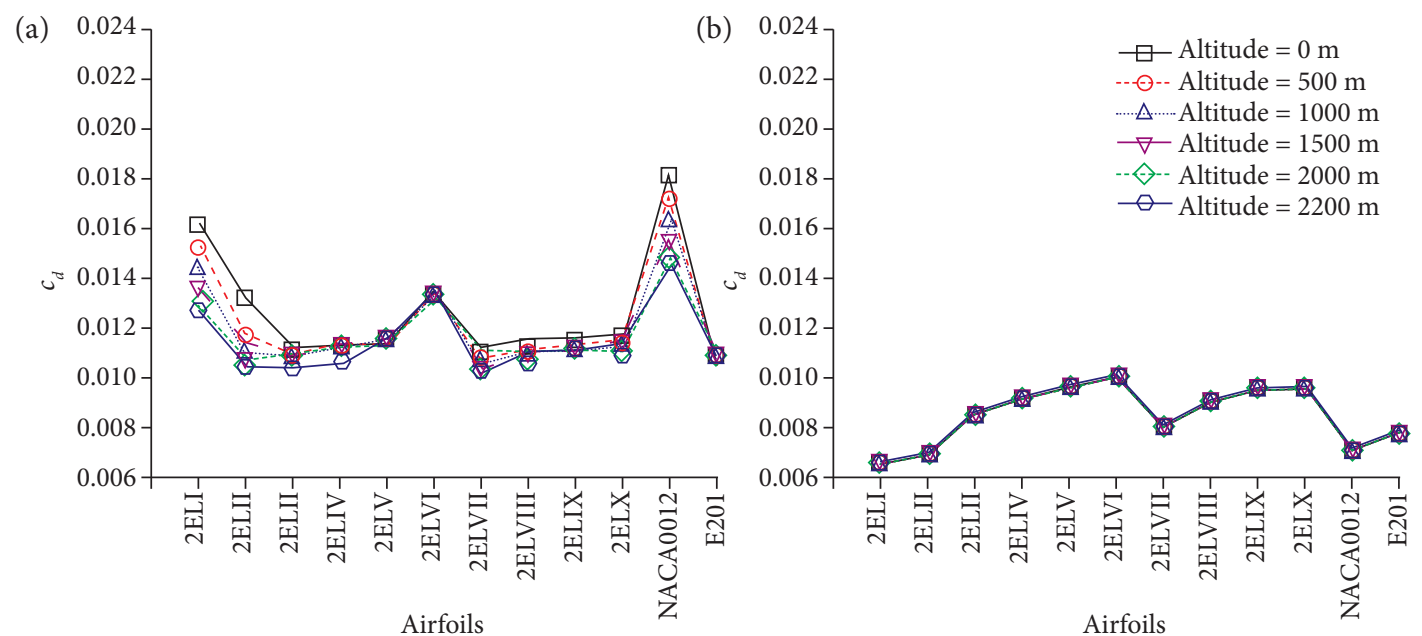

Figure 12. Drag coefficients for required lift coefficients (four-element). (a) $R e=2.5 \times 10^{5}$; (b) $R e=4.8 \times 10^{5}$.

Figure 13 compares the drag coefficient of the selected morphed airfoil with base and target airfoils. The selected morphed airfoils from the three formations showed lower drag coefficient compared to base airfoil for the required lift coefficient. 4ELVII airfoil showed 1.2 to $3.47 \%$ reduction in drag coefficient when compared to the target airfoil at a Reynolds number of $2.5 \times 10^{5}$, as listed in Table 7, whereas the selected morphed airfoils of two-element configuration showed a drag coefficient very close to the target airfoil, as seen in Fig.13a. As the Reynolds number was increased to $4.8 \times 10^{5}$, drag coefficients of all the selected morphed airfoils and base airfoil showed to be lower than the target airfoil, as depicted in Fig.13b. Among all the morphed airfoils, 4ELI was the best choice, and it showed a 13.2 to 15.17\% reduction in drag over the range of flight altitudes considered compared to the target airfoil, as listed in Table 7 . The drag coefficient $C_{\mathrm{D}}$ of the SUAV wing is given by

$$
C_{D}=c_{d}+C_{L}^{2} /(\pi \times A R \times e)
$$



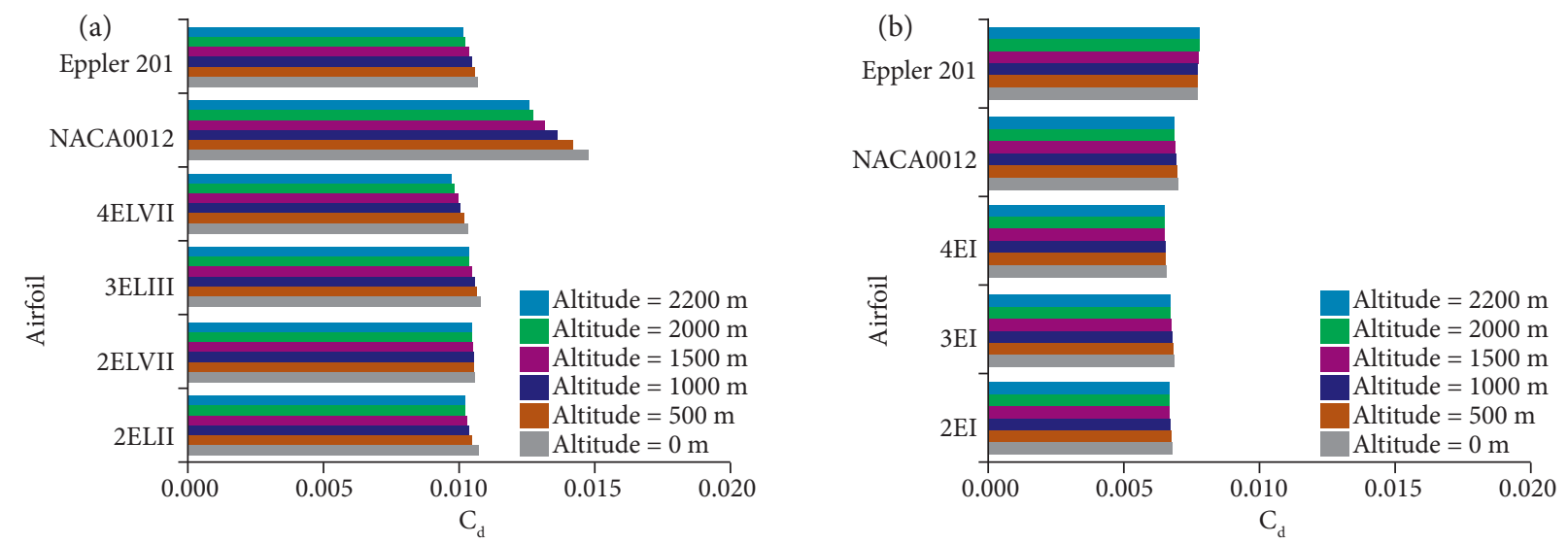

Figure 13. Drag coefficients of selected morphed airfoils with base and target airfoils at various altitudes. (a) Re $=2.5 \times 10^{5}$; (b) $\operatorname{Re}=4.8 \times 10^{5}$.

Table 7. Reduction in drag coefficient of selected morphed airfoils.

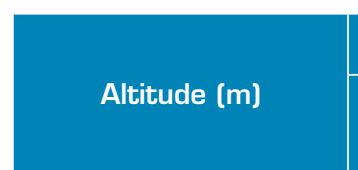

0

500

1000

1500

2000

2200

\begin{tabular}{|c|c|} 
& $\mathrm{Re}=2.5 \times 1$ \\
\hline$D_{\mathrm{BM}}$ \\
$\%$ reduction
\end{tabular}

39.340

37.193

35.127

32.621

30.454

29.596

$0^{5}-4 E$

$\%$

$D_{\mathrm{MT}}$
$\%$ reduction

1.212

1.963

2.522

2.891

3.265

3.479

\section{$R e=4.8 \times 10^{5}-4$ ELI airfoil}

\% reduction

7.533

7.263

6.994

6.728

6.518

6.453

\begin{tabular}{|c|c|}
\hline \% reduction \\
\hline 13.240 \\
\hline 13.696 \\
14.142 \\
14.577 \\
15.002 \\
15.170 \\
\hline
\end{tabular}

The first term $P$-I of Eq. 7 depends on the airfoil, $i$. e., the drag coefficient of the airfoil, $c d$, and the second term $P$ - II depends on the wing planform. Assuming the planform to be of a rectangular shape, it is evident that camber morphing the airfoils intelligently using the suggested methodology can reduce the drag coefficient by 1.2 to $15.17 \%$ for the case considered.

\section{A CASE STUDY: RESIZING THE SUAV TO INCLUDE MASS PENALTY}

Including the morphing mechanism would always imply additional weight for actuation, resulting in an increased mass of the design, mass which might outweigh the benefits of morphing. Going a step further, a methodology to redesign the original specification aiming to get the same benefit with mass addition is proposed in the following. In order to account for the mass addition in the system due to morphing mechanism in the wing, the design specification was recomputed to have the same benefit of drag reduction at the Reynolds numbers considered.

This study is done under the assumption that increasing the wing volume to house the morphing mechanism will increase the weight of the material considered for building a generic SUAV. This increase in weight can be regarded as a mass penalty due to morphing mechanism. Consequently, the chord of the airfoil was increased to $0.305 \mathrm{~m}$, based on available literature (Woods et al 2014; Ajaj et al. 2016). The wing planform area was recomputed to house the morphing mechanism inside the wing, allowing the total weight of the SUAV to remain the same. Figure 9 compares the conceptual model of resized SUAV with the generic SUAV 
considered. For varying altitudes, the lift coefficients were fixed, and the velocity required for flight was computed, as listed in Table 8. Wing loading of the resized SUAV was estimated at $59.71 \mathrm{~N} / \mathrm{m}^{2}$. The design specifications of generic SUAV and the resized SUAV are listed in Table 9. From this case study, it can be seen that retrofitting a generic SUAV with a morphing wing would lead to mass penalty. A redesign including the mass penalty in the original empty weight by using better materials would lead to a better design, which would truly benefit from morphing.

Table 8. Recalculated flight velocity for morphing SUAV.

\begin{tabular}{|c|c|c|c|c|c|c|c|c|}
\hline \multirow{2}{*}{$\begin{array}{c}\text { Altitude } \\
\text { [m] }\end{array}$} & \multicolumn{3}{|c|}{$\mathrm{Re}=2.5 \times 10^{5}$} & \multicolumn{5}{|c|}{$R e=4.8 \times 10^{5}$} \\
\hline & $\begin{array}{c}\text { Velocity } \\
\text { [m/s] }\end{array}$ & $\begin{array}{c}C_{L} \\
\text { wing }\end{array}$ & $\begin{array}{c}c_{l} \\
\text { airfoil }\end{array}$ & $\begin{array}{c}C_{d} \\
\text { airfoil }\end{array}$ & $\begin{array}{c}\text { Velocity } \\
\text { [m/s] }\end{array}$ & $\begin{array}{c}\boldsymbol{C}_{L} \\
\text { wing }\end{array}$ & $\begin{array}{c}c_{l} \\
\text { airfoil }\end{array}$ & $c_{d}$ airfoil \\
\hline 0 & 11.973 & 0.680 & 0.8501 & 0.01101 & 22.989 & 0.184 & 0.2306 & 0.00670 \\
\hline 500 & 12.456 & 0.660 & 0.8244 & 0.01082 & 23.915 & 0.179 & 0.2236 & 0.00667 \\
\hline 1000 & 12.963 & 0.639 & 0.7993 & 0.01064 & 24.889 & 0.173 & 0.2168 & 0.00665 \\
\hline 1500 & 13.497 & 0.620 & 0.7747 & 0.01047 & 25.914 & 0.168 & 0.2101 & 0.00662 \\
\hline 2000 & 14.059 & 0.600 & 0.7506 & 0.01032 & 26.994 & 0.163 & 0.2036 & 0.00660 \\
\hline 2200 & 14.292 & 0.593 & 0.7411 & 0.01027 & 27.441 & 0.161 & 0.2010 & 0.00659 \\
\hline
\end{tabular}

Table 9. Design data for resized SUAV.

\begin{tabular}{|c|c|c|}
\hline Specifications & Generic SUAV & Resized SUAV \\
\hline Wing loading $\left(\mathrm{N} / \mathrm{m}^{2}\right)$ & 95 & 59.71 \\
\hline Chord $(\mathrm{m})$ & 0.2418 & 0.305 \\
\hline Span $(\mathrm{m})$ & 1.451 & 1.830 \\
\hline Aspect ratio & 6 & 6 \\
\hline Area $\left(\mathrm{m}^{2}\right)$ & 0.351 & 0.558 \\
\hline Weight $(\mathrm{N})$ & 33.326 & 33.331 \\
\hline
\end{tabular}

\section{CONCLUSIONS}

Discrete element camber morphing methodology was adopted in this work to morph a given base airfoil to a specific target airfoil, and aerodynamic performances of the morphed airfoils were computed numerically. Suitable morphed airfoils were selected for the design specifications of generic SUAV, and the benefits of camber morphing were evaluated. The generic SUAV was resized a to morphing SUAV in order to account for the mass added to accommodate the morphing mechanism and yet maintain the same aerodynamic benefits brought by morphing. Based on this study, the following conclusions were drawn:

- Target airfoil (Eppler 201) performance was almost achieved by combinations of 5 to 8 morphed airfoils from each formation for both Reynolds numbers of interest. Four element-formations can also morph as two- and three-element formations, because of the common morphing locations for the case considered;

- As the Reynolds number is increased, the morphed airfoil with the maximum aerodynamic efficiency changes. Both the morphed airfoils 3ELV and 4ELX achieve their maximum aerodynamic efficiencies at $5.5^{\circ}$ for a Reynolds number of $2.5 \times 10^{5}$, and at 5 and $4^{\circ}$, respectively, for $4.8 \times 10^{5}$; 
- On morphing NACA 0012, the maximum aerodynamic efficiency of morphed airfoils occurs earlier than on Eppler 201, and is 3.5 to $6 \%$ lower than that of Eppler 201. It is also possible to have the same aerodynamic efficiency as that of the target airfoil with drag penalty by selecting morphed airfoils with high camber from Table 1 . Morphed airfoils from four-element formation achieve the maximum aerodynamic efficiencies for both the Reynolds numbers considered.

- It is sufficient to have three morphing locations to morph the base airfoil into the target airfoil. Two locations can be at maximum thickness position and maximum camber position as those of the target airfoil, and the other location can be chosen as the conventional plain flap position.

- From the pool of morphed airfoils, 4ELVII and 4ELI are found to be suitable for specifications of a selected generic SUAV design,, and for an altitude ranging from 0 to $2200 \mathrm{~m}$. 4ELVII airfoil, which has higher camber, performs better at a Reynolds number of $2.5 \times 10^{5}$, while the 4ELVI airfoil, with lower camber, performs better at a Reynolds number of $4.8 \times 10^{5}$. This indicates that, as Reynolds number increases, airfoils with lower camber seem to perform better.

- For the generic SUAV considered, morphing the airfoil can reduce the drag coefficient by $15.17 \%$, when compared to the target airfoil, for the same design lift coefficients corresponding to the flight Reynolds number and the altitude variation. This reduction in drag coefficients increases the aerodynamic efficiency and reduces the power required for the flight in the loiter and cruise phases.

- The generic SUAV is resized to morphing SUAV in order to account for mass addition in the system due to morphing. For same performance benefits, wing loading and velocity of the flight are modified. Wing loading of morphing SUAV is reduced by $37 \%$ compared to generic SUAV.

- There is a 58.7\% increase in wing area of morphing SUAV compared to generic SUAV, with a negligible difference in weight. This suggests that mass addition in the system due to morphing has to be taken care during the design stage of the vehicle by accounting for them into empty weight, i. e., structural and propulsion system. Over the range of flight altitudes, flight velocity of the resized SUAV is reduced by about $20.7 \%$ compared to generic SUAV.

- Conceptual design stage of SUAV has to account for the morphing parameters based on the methods of morphing.

Further studies are required to formulate new design procedures for sizing the morphing SUAV. A separate database has to be created for morphing airfoil based on type, methods of morphing and the base and target airfoils of choice.

\section{AUTHORS' CONTRIBUTION}

Conceptualization, Kumar TRS, Venugopal S and Ramakrishnananda B; Investigation, Kumar TRS and S.Vijay; Writing - Original Draft, Kumar TRS and Vijay S; Writing - Review and editing, Kumar TRS, and Ramakrishnananda B; Supervision, Venugopal S.

\section{REFERENCES}

Aftab SMA, Mohd Rafie AS, Razak NA, Ahmad KA (2016) Turbulence model selection for low Reynolds number flows. PLoS ONE 11(4):115. http://doi.org/10.1371/journal.pone.0153755

Ajaj RM, Beaverstock CS, Friswell MI (2016) Morphing aircraft: The need for new design philosophy. Aerosp Sci Technol 49(1):154-166. http://doi.org/10.1016/j.ast.2015.11.039

ANSYS FLUENT: user's guide online: c29 Jan 2009. ANSYS Inc; [accessed 2014 November 5]. http://www.afs.enea.it/project/ neptunius/docs/fluent/html/ug/main_pre.htm

Barbarino S, Bilgen 0, Friswell Ml, Ajaj RM, Inman DJ (2011) A review of morphing aircraft. J Intell Mater Syst Struct 22(9):823-877. http://doi.org/10.1177/1045389X11414084

Counsil JNN, Boulama KG (2013) Low-Reynolds-number aerodynamic performance of NACA 0012 and Selig-Donovan 7003 airfoils. J Aircr 50(1):204-216. http://doi.org/10.2514/1.C031856 
Cross A (1989) Captive carry testing of remotely piloted vehicles. In: Mueller TJ, editor. Low Reynolds Number Aerodynamics. Lecture Notes in Engineering. Springer-Verlag 54:1-12

Drela M (1989) XFOIL: An analysis and design system for low Reynolds number airfoils. In: Mueller TJ, editor. Low Reynolds Number Aerodynamics. Lecture Notes in Engineering - Springer-Verlag 54:1-12.

Friswell MI (2014) Morphing aircraft: an improbable dream? Proceedings of the ASME 2014 Conference on Smart Materials, Adaptive Structures and Intelligent Systems: Newport, USA. https://doi.org/10.1115/SMASIS2014-7754

Hansen KL, Kelso RM, Choudhry A, Arjomandi M (2014) Laminar separation bubble effect on the lift curve slope of an airfoil. Proceedings of the 19th Australasian Fluid Mechanics Conference, Melbourne: Australia.

Ko SH, Bae JS, Rho JH (2014) Development of a morphing flap using shape memory alloy actuators: the aerodynamic characteristics of a morphing flap. Smart Mater Struct 23(7):1-21. http://doi.org/10.1088/0964-1726/23/7/074015

Langtry RB, Menter FR (2005) Transition modeling for general CFD applications in aeronautics. Proceedings of the 43 ${ }^{\text {rd }}$ AIAA Aerospace Sciences Meeting and Exhibit, Reno, USA. https://doi.org/10.2514/6.2005-522

Langtry RB, Menter FR, Likki SR, Suzen YB, Huang PG, Völker SA (2006) A correlation-based transition model using local variables — Part II: Test cases and industrial applications. ASME-J Turbomach 128(3):423-434. https://doi.org/10.1115/1.2184353

Leoviriyakit K, Jameson A (2004) Case studies in aero-structural wing planform and section optimization. Proceedings of the $22^{\text {nd }}$ Applied Aerodynamics Conference and Exhibit, Rhode Island, USA. https://doi.org/10.2514/6.2004-5372

MATLAB ver.8.1: help online. c1994-2018. The Mathworks, Inc; [accessed 2013 December 18]. https://in.mathworks.com/help/index.htm McCormick BW (1995) Aerodynamics, Aeronautics, and Flight Mechnics. 2nd edition. New York: John Wiley \& Sons Inc.

Menter FR, Langtry RB, Likki SR, Suzen YB, Huang PG, Völker S (2006) A correlation based transition model using local variables — Part I: Model formulation. ASME-J Turbomach 128(3):413-422. https://doi.org/10.1115/1.2184352

Morgado J, Vizinho R, Silvestre MA, Páscoa JC (2016) XFOIL vs CFD performance predictions for high lift low Reynolds number airfoils. Aerosp Sci Technol 52(1): 207-214. https://doi.org/10.1016/j.ast.2016.02.031

MYSQL ver.5.7: open-source software online. c2018. Oracle Corporation and/or its affiliates; [accessed 2017 July 9]. https://dev. mysql.com/doc/

Poonsong P (2004) Design and analysis of a multi-section variable camber wing (MS thesis). College Park: The University of Maryland

Kumar RS, Sivakumar V, Ramakrishnananda B, Arjhun AK, Suriyapandiyan (2017) Numerical investigation of two element camber morphing airfoil in low Reynolds number flows. J Eng Sci Technol 12(7): 1939-55.

Sadraey MH (2012) Aircraft design: A systems engineering approach. 1st edition. New York: John Wiley \& Sons Inc.

Short SR (2008) Modeling and analysis of active turbulators on low Reynolds number unmanned aerial vehicles (PhD thesis). Raleigh: North Carolina State University.

Torenbeek E (2013) Advanced aircraft design: Conceptual design, analysis and optimization of Subsonic Civil Airplanes. 1st edition. New York: John Wiley \& Sons Inc.

Van Ingen $\mathrm{JL}$ (2008) The $\mathrm{e}^{\mathrm{N}}$ method for transition prediction: Historical review of work at TU Delft. Proceedings of the $38^{\text {th }}$ Fluid Dynamics Conference and Exhibit, Seattle: Washington. doi: https://doi.org/10.2514/6.2008-3830

Vasista S, Tong L, Wong KC (2012) Realization of morphing wings: a multidisciplinary challenge. J Aircr 49(1): 11-28. doi: http://doi. org/10.2514/1.C031060

Wang Y (2015) Development of flexible-rib morphing wing system (MS thesis). Ontario: University of Toronto.

Woods BKS, Bilgen 0, Friswell MI (2014) Wind tunnel testing of the fish bone active camber morphing concept. J Intell Mater Syst Struct 25(7): 772-785. doi: http://doi.org/10.1177/1045389X14521700

XFLR5 ver.6.10.04: open-source software online. June 2017; [accessed 2017 Jun 27]. http://www.xflr5.com/xflr5.htm

XFOIL ver.6.99: open-source code and software online. Dec 2013; [accessed 2017 Jun 27]. http://web.mit.edu/drela/Public/web/xfoil/ 